doi:10.1136/heartjnl-2012-301877b.68

${ }^{1} \mathrm{R}$ Bastiaenen, ${ }^{*}{ }^{2} \mathrm{~V}$ Batchvarov, ${ }^{2} \mathrm{~A}$ Kiotsekoglou, ${ }^{2} \mathrm{~A}$ Zaidi, ${ }^{1} \mathrm{H}$ Gonna, ${ }^{2} \mathrm{G}$ Stavropoulos, ${ }^{2} \mathrm{E}$ R Behr, ${ }^{1} \mathrm{M} M$ Gallagher. 'St George's Hospital NHS Trust, UK; ${ }^{2}$ St George's University of London, London, UK

Introduction A gold standard test for arrhythmogenic right ventricular cardiomyopathy (ARVC) does not exist and diagnosis relies on meeting Task Force criteria. Sudden death remains the first clinical presentation in up to $23 \%$ of subjects. In ischaemic heart disease prolongation of the ventricular ectopic OS interval (VEOSI) has been shown to correlate with presence and severity of myocardial disease. We evaluated the significance of VEOSI in patients with ARVC.

Methods We selected 3 cohorts for 12 lead 24-h Holter monitoring: 51 normal controls (41.7 \pm 14.8 years; $55 \%$ male); 27 patients with definite ARVC by Task Force criteria (46.4 \pm 13.1 years; $70 \%$ male); 10 patients with borderline ARVC and a confirmed pathogenic mutation and/or definitely affected first degree relative ( $34.6 \pm 13.0$ years; $50 \%$ male). All ventricular ectopics (VE) were reviewed and VEOSI was measured for each VE morphology. The longest VE duration was recorded as VEOSI max.

Results VEOSI max was significantly longer in definite ARVC compared with borderline ARVC and normal controls $(208.8 \pm 18.6 \mathrm{~ms}, \quad 183.7 \pm 12.9 \mathrm{~ms}$ and $155.0 \pm 14.4 \mathrm{~ms}$ respectively; $\mathrm{p}<0.001)$. VEOSI max was also significantly longer in borderline ARVC compared with normal controls $(p=0.002)$. When the upper normal limit for VEOSI max was defined as $170 \mathrm{~ms}$ there was $97 \%$ sensitivity and $93 \%$ specificity for diagnosis of ARVC, including $9 / 10$ correct diagnoses in the borderline ARVC group.

Conclusion Maximal VEQSI duration is significantly longer in definite ARVC compared with normal controls, and intermediate in ARVC patients with early disease. VEOSI max $>170 \mathrm{~ms}$ has high sensitivity and specificity for the diagnosis of ARVC and may be particularly useful in borderline disease.

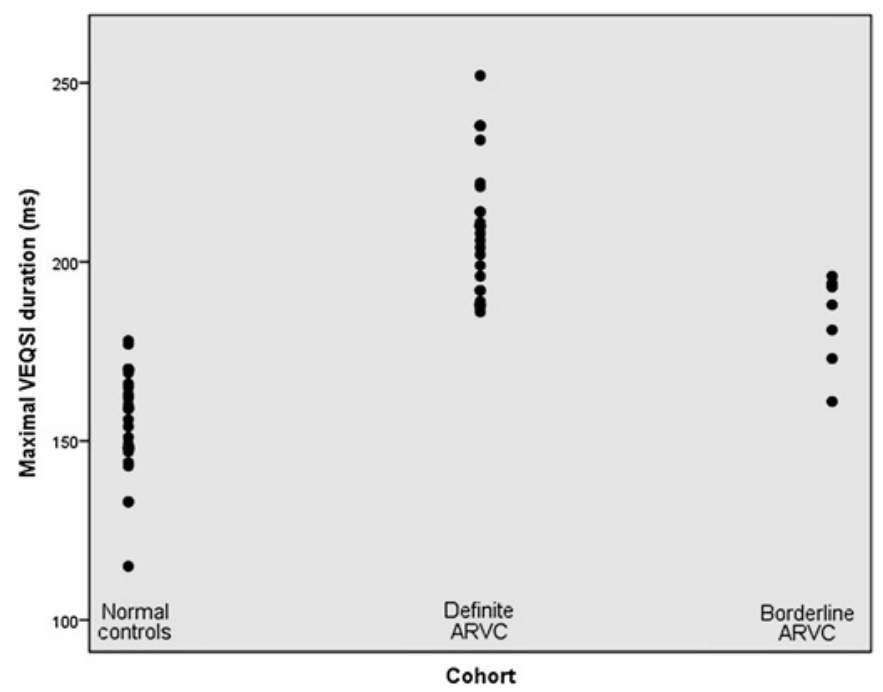

Abstract 068 Figure 1

\section{SYSTEMATIC REVIEW OF 1142 ADMISSIONS WITH ACUTE HEART FAILURE REVEALS HIGH FREQUENCY OF TRANSTHYRETIN V122I CARDIAC AMYLOIDOSIS IN AFRO- CARIBBEAN PATIENTS}

doi:10.1136/heartjnl-2012-301877b.69

${ }^{1} \mathrm{~J}$ Dungu, * ${ }^{1} \mathrm{M}$ S O'Donnell, ${ }^{2} \mathrm{P} N$ Hawkins, ${ }^{1} \mathrm{~L} \mathrm{~J}$ Anderson. ${ }^{1}$ St George's University of London, London, UK; ${ }^{2}$ National Amyloidosis Centre, UK

Background The genetic mutation encoding transthyretin (TTR) isoleucine 122 (V122I) is present in 3.9\% of African-Americans and associated with cardiac TTR amyloidosis, but penetrance is unknown. Little is known about the frequency or clinical phenotype of TTR V122I amyloidosis in the British Afro-Caribbean population.

Methods We reviewed the primary diagnoses of 1142 patients admitted with heart failure between September 2005 and February 2011. The diagnosis was supported by echocardiography, cardiac MRI (in patients without contraindications) and genetic testing; endomyocardial biopsies were performed in 68 patients $(6 \%)$ in whom amyloidosis was suspected or uncertainty about diagnosis remained. Survival analysis was performed to August 2011.

Results The median age was 72 years (range 18-98) with male $(66.7 \%)$ and Caucasian (71.0\%) predominance. Ischaemic cardiomyopathy (ICM) was the primary diagnosis in 428 patients $(37 \%)$. There were 170 Afro-Caribbean patients (14.9\%) among whom ICM was less common (22 patients $(13 \%), p<0.01)$. Seventeen AfroCaribbean patients $(10 \%)$ were confirmed to have cardiac ATTR V122I amyloidosis. Survival of Afro-Caribbean patients with ICM and ATTR V122I amyloidosis was similar (45 vs 36 months, $\mathrm{p}=0.54)$, but overall survival $(\mathrm{n}=1142)$ was significantly inferior in cardiac amyloidosis compared to non-amyloid cardiomyopathy (34 vs 59 months, $\mathrm{p}<0.01$ )

Conclusion ATTR V122I amyloidosis is an important cause of heart failure in the British Afro-Caribbean population, but it is commonly misdiagnosed as hypertensive cardiomyopathy. Diagnosis requires specialist multidisciplinary investigation including CMR, genetic testing and histology, enabling appropriate management in an era when novel treatments for amyloidosis are entering the clinic.
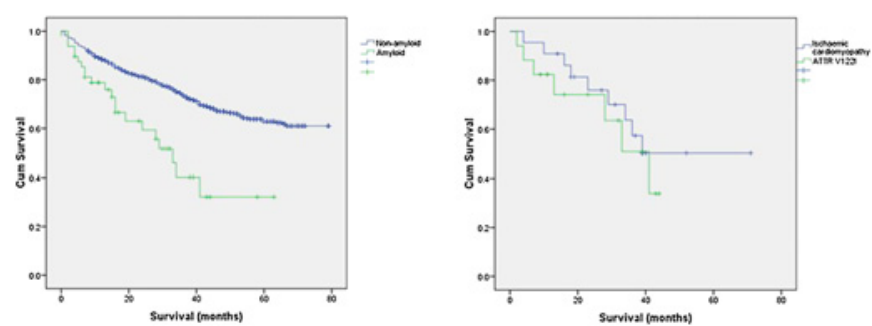

Abstract 069 Figure 1 Kaplan-Meier curves for all patients $(n=1142)$ demonstrating significantly inferior survival in cardiac amyloidosis compared to non-amyloid cardiomyopathy $(p<0.01)$. Kaplan-Meier curves in Afro-Caribbean patients $(\mathrm{N}=170)$ demonstrating no significant difference in survival between ischaemic cardiomyopathy and ATTR V122I $(p=0.54)$. 
Abstract 069 Table 1

\begin{tabular}{lccc}
\hline Black ethnicity data & $\begin{array}{l}\text { Afro-Caribbean } \\
\text { patients } \mathbf{N = 1 7 0}\end{array}$ & $\begin{array}{l}\text { All other } \\
\text { patients N=972 }\end{array}$ & p Value \\
\hline Age & $71(53-77)$ & $73(63-81)$ & $<0.01$ \\
Male gender & $110(64.7 \%)$ & $652(67.1 \%)$ & $<0.01$ \\
Ischaemic cardiomyopathy & $22(12.9 \%)$ & $406(41.8 \%)$ & $<0.01$ \\
Non-ischaemic (total) & $148(87.1 \%)$ & $566(58.2 \%)$ & $<0.01$ \\
Amyloid (AL and TTR) & $27(15.9 \%)$ & $21(2.2 \%)$ & $<0.01$ \\
ATTR V122I & $\mathbf{1 7}(\mathbf{1 0} \%)$ & $\mathbf{4}(\mathbf{0 . 4 \% )}$ & $<\mathbf{0 . 0 1}$ \\
Dilated cardiomyopathy & $46(27.1 \%)$ & $179(18.4 \%)$ & $<0.01$ \\
Hypertensive heart disease & $32(18.8 \%)$ & $68(7.0 \%)$ & $<0.01$ \\
\hline
\end{tabular}

\section{ENZYME REPLACEMENT THERAPY IMPROVES CARDIAC FEATURES OF FABRY DISEASE}

doi:10.1136/heartjnl-2012-301877b.70

M Motwani, ${ }^{*}$ S Banypersad, P Woolfson, S Waldek. Salford Royal Hospital NHS Foundation Trust, UK

Introduction Fabry disease (FD) is an X linked deficiency of $\alpha$-galactosidase A which leads to an accumulation of globotriaosylceramide (GL-3) throughout the body, particularly in the heart, brain and kidneys. Although left ventricular hypertrophy (LVH) in FD can improve with enzyme-replacement therapy (ERT), the response is difficult to predict. Furthermore, the response of other cardiac features such as aortic dilatation and ECG changes are poorly understood.

Methods A local registry of 66 patients with FD was studied. ECG, echocardiogram and Fabry Outcome Survey-Mainz Severity Score

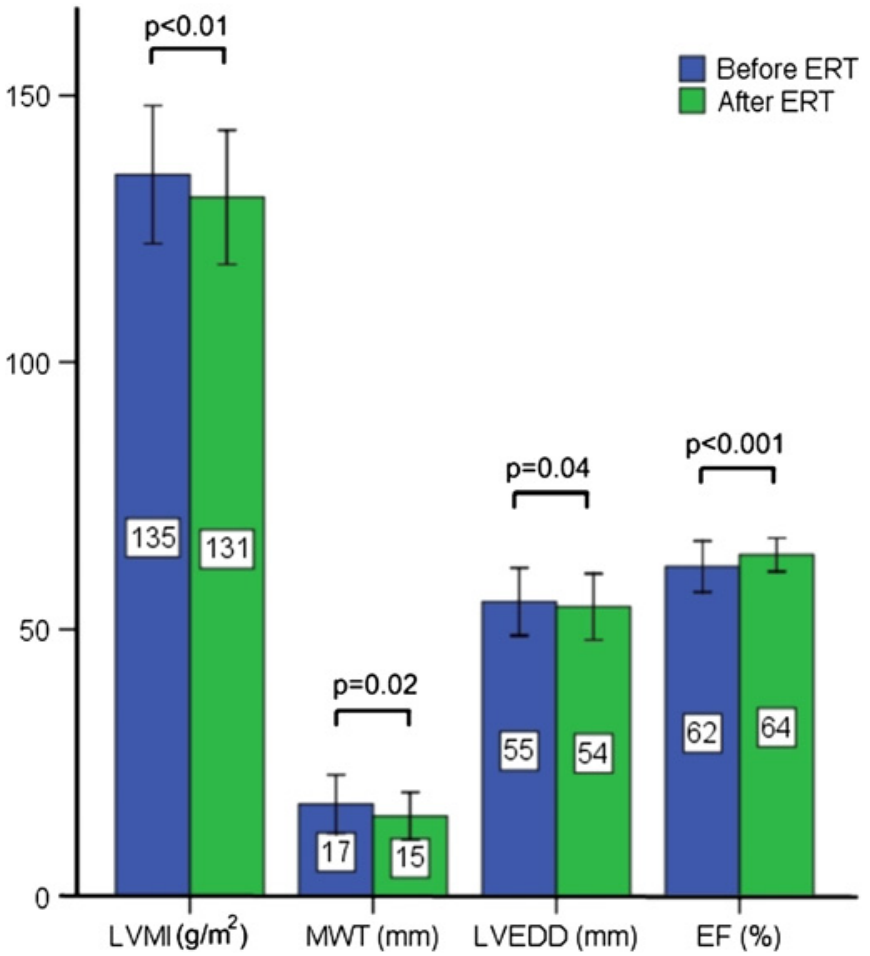

Abstract 070 Figure 1 Effect of enzyme replacement therapy (ERT) on LV morphology and function in patients with LVH at baseline. Left ventricular mass index (LVMI), maximal wall thickness (MWT), LV enddiastolic diameter (LVEDD) and ejection fraction all showed significant improvements (all $p$ values $<0.05$ ) at the end of follow-up (median 3 years). [Values shown are mean \pm SD].
Index (FOS-MSSI) data were compared between baseline and after long-term ERT (median 36 months).

Results In patients with LVH $(n=42)$, left ventricular mass index (LVMI), maximal wall thickness (MWT), left ventricular enddiastolic diameter (LVEDD) and ejection fraction (EF) were all seen to improve after ERT (LVMI: $135 \pm 13$ vs $133 \pm 13 \mathrm{~g} / \mathrm{m}^{2}$, MWT: $17 \pm 6$ vs $16 \pm 5 \mathrm{~mm}$, LVEDD: $55 \pm 6$ vs $54 \pm 6 \mathrm{~mm}$; EF: $62 \pm 5$ vs $64 \pm 3 \%$; $\mathrm{p}<0.05$ ) (Abstract 070 figure 1). In the entire patient group, $P Q$ interval and $\mathrm{P}$ wave duration significantly increased with ERT (PQ: $131 \pm 13$ vs $144 \pm 13 \mathrm{~ms}$, P: $76 \pm 5$ vs $90 \pm 6 \mathrm{~ms}$; p values <0.001); QTc interval significantly decreased $(418 \pm 18$ vs $410 \pm 15 \mathrm{~ms} ; \mathrm{p}<0.001)$; and median FOS-MSSI score fell from 16 to $14(\mathrm{p}<0.001)$ (Abstract 070 figure 2). On logistic-regression analysis, none of the recorded baseline features (age, gender, LVMI, MWT, LVEDD, aortic diameter, EF, PQ interval, P wave duration, ORS duration, OT interval, Romhilt-Estes score or FOS-MSSI) predicted improvements in LVH or FOS-MSSI with ERT ( $p>0.05)$.

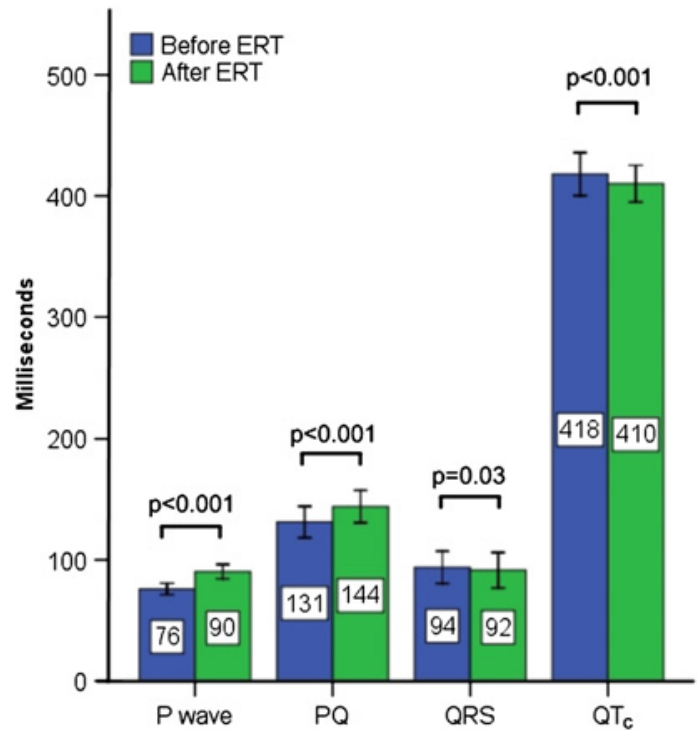

Abstract 070 Figure 2 Effect of enzyme replacement (ERT) on the conduction system. There was a significant increase in $\mathrm{P}$ wave duration and PQ interval from baseline; there was a significant decrease in QRS width and OTc interval from baseline at the end of follow-up (median 3 years). [Values shown are mean \pm SD].

Conclusions ERT improved LV morphology and function in patients with LVH- but there was no relationship between age, gender, FOSMSSI or baseline ECG/TTE features and the response. ERT also normalised long OTc intervals, short PQ intervals and short P waves; and reduced disease burden (FOS-MSSI).

\section{CONCENTRIC HYPERTROPHIC REMODELLING AND SUBENDOCARDIAL DYSFUNCTION IN MITOCHONDRIAL DNA POINT MUTATION CARRIERS}

doi:10.1136/heartjnl-2012-301877b.71

M G D Bates,* K G Hollingsworth, J Newman, D G Jakovljevic, B D Keavney, A M Blamire, G A MacGowan, P F Chinnery, D M Turnbull, R W Taylor, M I Trenell, G S Gorman. Newcastle University, UK

Background Cardiomyopathy is an independent predictor of morbidity and early mortality in mitochondrial DNA disease, and 